\title{
Hydrothermal Carbonization of Nonylphenol Ethoxylates Waste Liquid for Energy Source Generation
}

\author{
Yongquan Ge1, Wenqi Zhang1* ${ }^{*}$, Gang Xue ${ }^{2}$, Pinhua Rao ${ }^{1}$ \\ ${ }^{1}$ College of Chemistry and Chemical Engineering, Shanghai University of Engineering Science, Shanghai, China \\ ${ }^{2}$ College of Environmental Science and Engineering, Donghua University, Shanghai, China \\ Email: *zhangwenqi_hit@163.com
}

Received 21 November 2015; accepted 22 December 2015; published 25 December 2015

Copyright (C) 2015 by authors and Scientific Research Publishing Inc.

This work is licensed under the Creative Commons Attribution International License (CC BY). http://creativecommons.org/licenses/by/4.0/

c) (i) Open Access

\begin{abstract}
Nonylphenol polyethoxylates (NPEOs) are widely used as nonionic surfactants in many industry fields. High concentration NPEOs waste water is produced in some production processes. It is often treated to realize reduction by distillation. Therefore, NPEOs waste liquid with higher concentration is produced and it is difficult to be treated by traditional water treatment process. In this study, hydrothermal carbonization process was used to convert NPEOs waste liquid to carbonaceous product (hydrochar) with sulfuric acid as additive in $24 \mathrm{~h}$ at $200^{\circ} \mathrm{C}$. The hydrochar was characterized by scanning electron microscope, Fourier-transform infrared spectrometer and thermogravimetric analysis. The element composition and the high heat value of the hydrochar were similar to lignite, showing that it could be used as an alternative fuel.
\end{abstract}

\section{Keywords}

Nonylphenol Polyethoxylates, Hydrothermal Carbonization, Hydrochar, Alternative Fuel

\section{Introduction}

Nonylphenol polyethoxylates (NPEOs) are nonionic surfactants and widely used in detergents, herbicides, paints, pesticides, cosmetics and many other products [1]. They have entered the environment via industrial effluents and human sewage. In actual environments, NPEOs can be biodegraded to generate nonylphenol (NP) and short chain NPEOs which are more toxic, more lipophilic and more persistent than the parent substance [2] [3]. NP as an estrogen-similar endocrine disruptor has posed a potential threat to both the human health and ecological se-

"Corresponding author.

How to cite this paper: Ge, Y.Q., Zhang, W.Q., Xue, G. and Rao, P.H. (2015) Hydrothermal Carbonization of Nonylphenol Ethoxylates Waste Liquid for Energy Source Generation. American Journal of Analytical Chemistry, 6, 1059-1066.

http://dx.doi.org/10.4236/ajac.2015.613101 
curity.

Low concentration NPEOs in water environment can be treated by biological [4], advanced oxidation [5], photocatalytic [6] and adsorption [7] methods. However, some production processes produce high concentration NPEOs waste water. To realize reduction, it is often treated by distillation. Therefore, NPEOs waste liquid with higher concentration is produced. But it is difficult to be treated by above traditional water treatment process.

Hydrothermal carbonization (HTC) is a thermochemical process converting organic feedstock into carbonaceous product (hydrochar) under moderate temperatures $\left(180^{\circ} \mathrm{C}-350^{\circ} \mathrm{C}\right)$ and autogenous pressures in the presence of water [8]-[10]. Due to moderate reaction condition and low energy consumption, HTC process is suitable to convert high concentration waste liquid into hydrochar. Currently, it has not been reported that NPEOs waste liquid was treated by HTC process.

In this study, HTC process was used to convert NPEOs waste liquid to recovery hydrochar. The hydrochar was characterized by scanning electron microscope, Fourier-transform infrared microscope and thermo gravimetric analysis and evaluated as an alternative fuel.

\section{Experimental}

\subsection{Materiels}

The NPEOs waste liquid was obtained from the distillation process of a chemical enterprise in China. NPEOs and moisture content was about 60 and $40 \mathrm{wt} \%$, respectively. Sulfuric acid $\left(\mathrm{H}_{2} \mathrm{SO}_{4}, 96 \%\right)$ was purchased from Sinopharm Chemical Reagent Co., Ltd (China).

\subsection{Experimental Method}

In each batch experiment, $5 \mathrm{~mL}$ (about $5 \mathrm{~g}$ ) of NPEOs waste liquid was put into a non-stirred $40 \mathrm{ml}$ stainless steel Teflon-lined reactor with an external heater. The process conditions (dosage of additive, reaction temperature and reaction time) are summarized in Table 1 . The reactor was heated to the desired reaction temperature $\left(180^{\circ} \mathrm{C}\right.$ or $\left.200^{\circ} \mathrm{C}\right)$ with a heating rate of $10^{\circ} \mathrm{C} / \mathrm{min}$ [8]-[10]. The reactor temperature was maintained under its autogenic pressure for the desired reaction time (12 or $24 \mathrm{~h}$ ). Afterward, the reactor was cooled to room temperature and then raw product was obtained. The raw product was washed with $150 \mathrm{~mL}$ of distilled water. After filtered by filter paper, the hydrochar was dried at $105^{\circ} \mathrm{C}$ for $3 \mathrm{~h}$. The hydrochar was a black powder which could be used to test for different experimental characterizations without pretreatment. The hydrochar was characterized by scanning electron microscope, Fourier-transform infrared spectrometer elemental analyzer and thermogravimetric analysis. The yield of hydrochar was calculated using the following equations.

$$
\text { Hydrochar yield }(\%)=\frac{\text { Hydrochar weight }}{\text { NPEOs waste water weight }} \times 100 \% \text {. }
$$

\subsection{Characterization Methods}

Surface morphology was examined by scanning electron microscope (SEM) (HITACHI S-3400, Japan). Surface

Table 1. HTC process of different conditions.

\begin{tabular}{cccc}
\hline Sample & Sulfuric acid/mL & Temperature/ ${ }^{\circ} \mathbf{C}$ & Time/h \\
\hline 1 & 0 & 200 & 24 \\
2 & 1 & 200 & 24 \\
3 & 2 & 200 & 24 \\
4 & 3 & 200 & 24 \\
5 & 4 & 200 & 24 \\
6 & 5 & 200 & 24 \\
7 & 3 & 180 & 24 \\
\hline
\end{tabular}


functional groups were analyzed by Fourier-transform infrared spectrometer (FTIR) (Nicolet AVATAR 370, USA). The elemental composition was determined using elemental analyzer (vario EL cube III, Germany). Test methods for moisture, ash, volatile matter (VM) and fixed carbon (FC) were based on proximate analysis of coal (GB212-91, China). Thermogravimetric analysis (TGA) was carried out by thermogravimetric analyzer (STA PT-1000, Germany).

\section{Results and Discussion}

\subsection{HTC Conditions}

For sample 1, there was no change after HTC process as shown in Figure 1(a), implying that NPEOs was not carbonized without sulfuric acid as additive. For sample 2 and 3, some hydrochar formed but some NPEOs remained obviously as shown in Figure 1(b), showing that sulfuric acid played an important role on the reaction, but the dosage was not enough. For sample 4, 5 and 6, raw waste liquid was carbonized totally as shown in Figure 1(c), showing that NPEOs could be totally converted to hydrochar with enough sulfuric acid. The yield of sample 4, 5 and 6 were 57.30, 48.51 and $32.61 \mathrm{wt} \%$, respectively, suggesting that some hydrochar was destroyed by excessive sulfuric acid. For sample 7 and 8, some NPEOs remained obviously, suggesting that reaction temperature was not reduced and reaction time was not shorted.

In summary, sample 4 was most representative due to least dosage of additive and highest product yield. The optimum condition was that $5 \mathrm{ml}$ of NPEOs waste liquid was totally solidified with $3 \mathrm{ml}$ of sulfuric acid at $200^{\circ} \mathrm{C}$ for $24 \mathrm{~h}$. In the next, the physical and chemical characteristics of sample 4 were investigate.

\subsection{Characteristics of Hydrochar}

\subsubsection{SEM}

Figure 2 showed the surface morphologies of the hydrochar at different magnifications. In the traditional HTC process, the structure of hydrochar is related to the water-solubility of feedstock. For water-soluble feedstock, hydrochar was tend to be spherical particles, such as cellulose [11] [12]. As shown in Figure 2(a), the hydrochar appeared as blocks with agglomerated particles attached. The formation of blocks may due to the lack of available space for particle growth at the high concentration of NPEOs. With the concentration decreasing, small particles formed. As shown in Figure 2(b), some particles were hollow hemispherical with small blocks attached. This may suggest that the spherical particles was hollow and some of them was broken. As shown in Figure 2(c), smaller agglomerated particles were also spherical. As shown in Figure 2(d), small spherical particles and blocks were attached to the big spherical particles. The formation of small blocks may result from the big blocks and particles which broke in HTC process.

\subsubsection{FTIR Spectra}

Various functional groups of the hydrochar were characterized by FTIR. Figure 3 shows the FTIR spectra of the hydrochar. The band at $3438 \mathrm{~cm}^{-1}$ was attributed to -OH stretching vibration in hydroxyl groups. Asymmetric and symmetric -C-H stretching of methylene groups were identified at $2922 \mathrm{~cm}^{-1}$ and $2864 \mathrm{~cm}^{-1}$ [13], respectively.

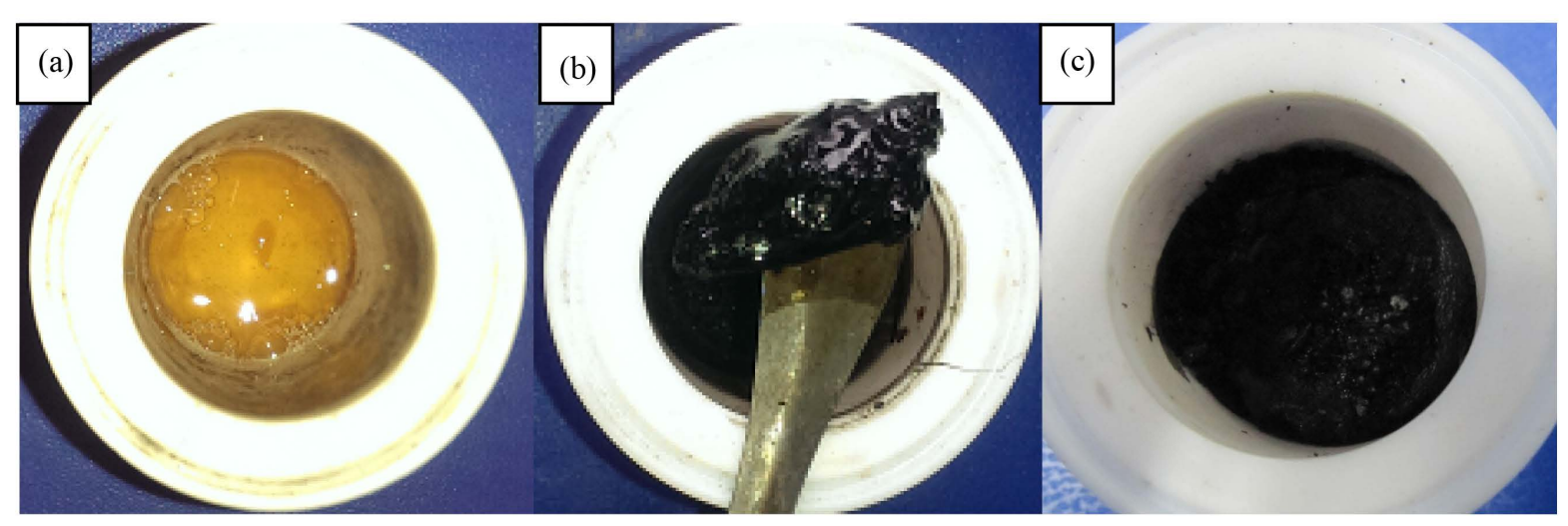

Figure 1. Appearance of the products: (a) Liquid; (b) Solid liquid mixture; (c) Solid. 


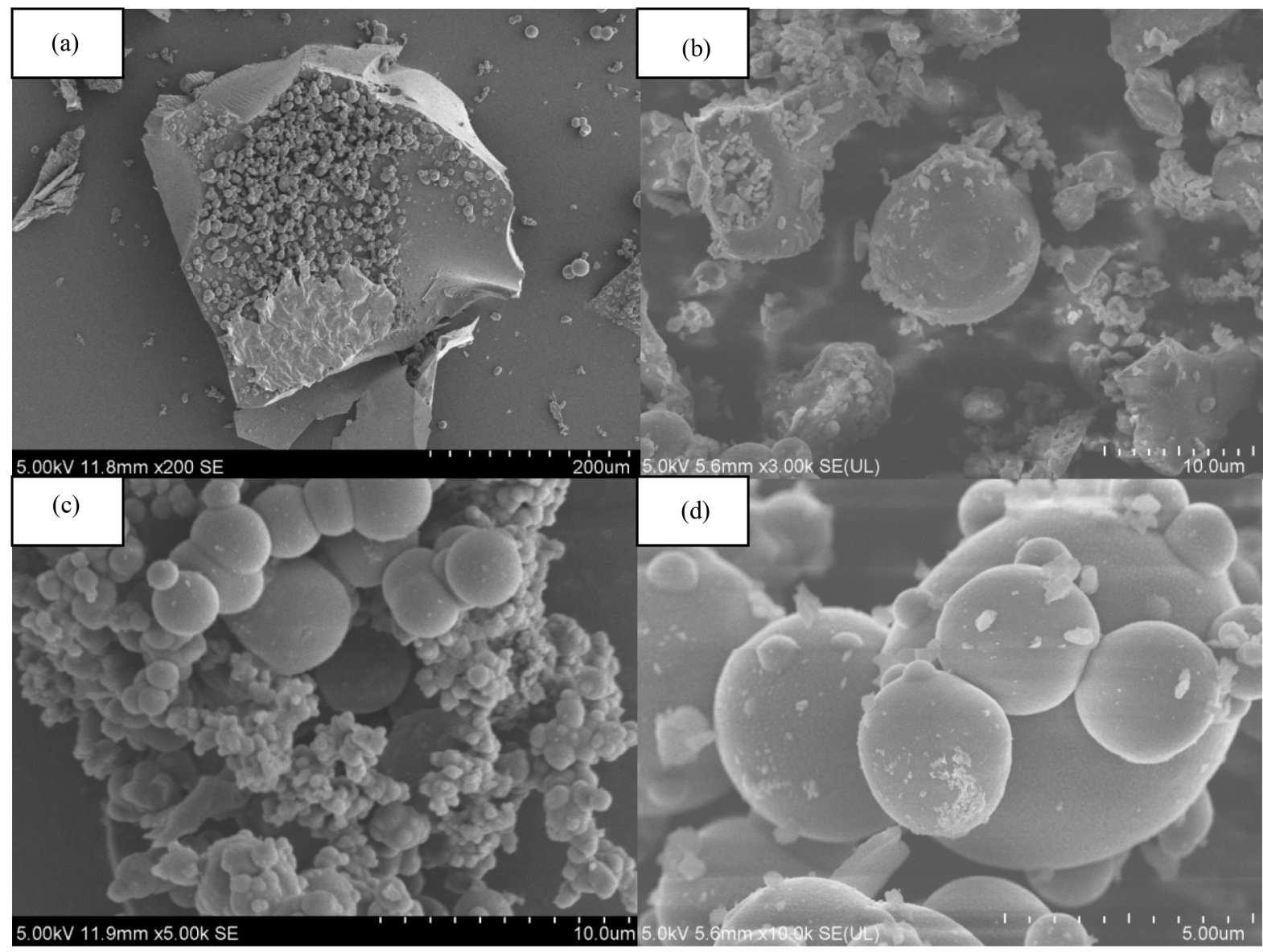

Figure 2. SEM images of the hydrochar.

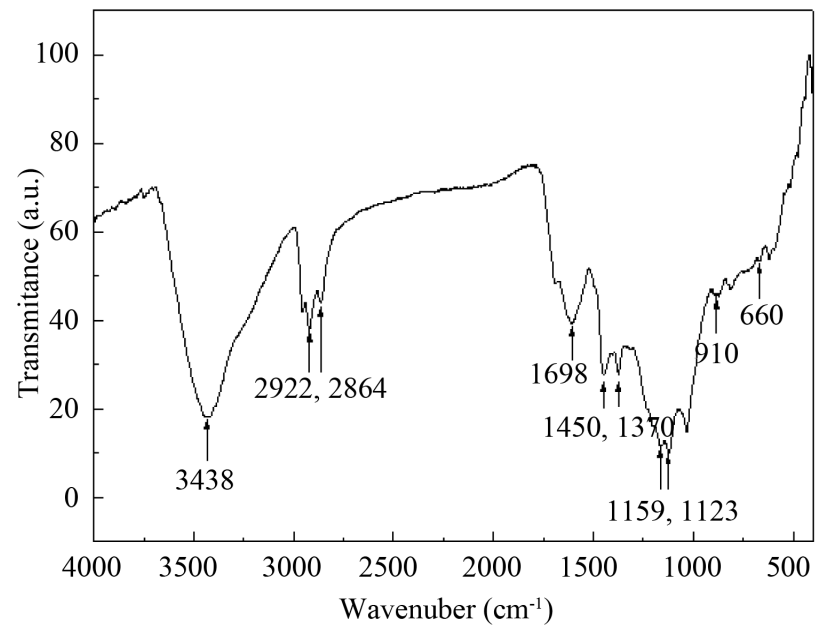

Figure 3. FTIR spectra of the hydrochar.

The band at $1698 \mathrm{~cm}^{-1}$ implied the stretching vibration of $-\mathrm{C}=\mathrm{O}$ in ketone and amide groups [14]. The peak at $1450 \mathrm{~cm}^{-1}$ was assigned to the $-\mathrm{C}=\mathrm{O}$ stretching in aromatic ring carbons. In addition, the peak at $910 \mathrm{~cm}^{-1}$ was attributed to the out-of-plane bending vibration in aromatic nucleus - $\mathrm{CH}$ structure, which suggested the occurrence of aromatization during HTC [15]. The peaks at $1159 \mathrm{~cm}^{-1}$ and $1123 \mathrm{~cm}^{-1}$ were attributed to symmetric and asymmetric stretching of sulfonated groups, respectively. S-O stretching at $1370 \mathrm{~cm}^{-1}$, asymmetric C-S 
stretching at $910 \mathrm{~cm}^{-1}$ and S-O bending vibration at $660 \mathrm{~cm}^{-1}$ related to sulfonic acid group [16]. These suggested the introduction of sulfonic acid group in the HTC process.

\subsubsection{Ultimate Analysis}

The ultimate analysis of the raw waste liquid and hydrochar are listed in Table 2. By comparing the raw waste liquid, $\mathrm{C}$ content of the hydrochar increased from 42.17 to $69.48 \mathrm{wt} \%$, showing that $\mathrm{C}$ was enriched in the HTC process. $\mathrm{H}$ and $\mathrm{O}$ content of the raw waste liquid decreased from 10.04 and 47.43 to 5.32 and $20.10 \mathrm{wt} \%$, respectively, suggesting the dehydration in the HTC process. S content of the hydrochar increased from 0.00 to $4.80 \mathrm{wt} \%$, proving that sulfonic acid group was formed in the HTC process.

Figure 4 indicates the classification of the hydrochar as a solid fuel based upon Van Krevelen diagram [17]. For comparison, H/C vs. O/C atomic ratios of Anthracite, bituminous, lignite, and peat were also plotted in Van Krevelen diagram. The hydrochar was in the region of lignite, implying that its element composition was similar to lignite.

\subsubsection{Proximate Analyses}

Table 3 presents the proximate analyses and the high heat values (HHV) of the hydrochar. The fuel ratio (FC/ VM) ranks carbonaceous product as an alternative fuel. Channiwala and Parikh [18] have developed a unified correlation to predict HHV of solid fuel expressed by elemental composition:

Table 2. Ultimate analysis of the raw waste liquid and hydrochar.

\begin{tabular}{cccc}
\hline & & Raw waste liquid & Hydrochar \\
\hline & $\mathrm{C}$ & 42.17 & 69.48 \\
Ultimate analysis (wt\%) & $\mathrm{H}$ & 10.04 & 5.32 \\
& $\mathrm{O}$ & 47.43 & 20.10 \\
& $\mathrm{~N}$ & 0.36 & 0.30 \\
& $\mathrm{~S}$ & 0.00 & 4.80 \\
\hline \multirow{2}{*}{ Atomic ratio } & $\mathrm{H} / \mathrm{C}$ & 2.85 & 0.92 \\
& $\mathrm{O} / \mathrm{C}$ & 0.84 & 0.27 \\
\hline
\end{tabular}

Table 3. Proximate analyses and HHV of the hydrochar.

\begin{tabular}{cccccccc}
\hline & \multicolumn{3}{c}{ Proximate analysis $(\mathbf{w t} \%, \mathbf{d b})$} & & Fuel ratio & HHV \\
\hline & Moisture & Ash & VM & FC & (FC/VM) & (MJ/kg) \\
\hline Hydrochar & 3.80 & 5.60 & 43.09 & 47.51 & 1.10 & 28.38 \\
\hline
\end{tabular}

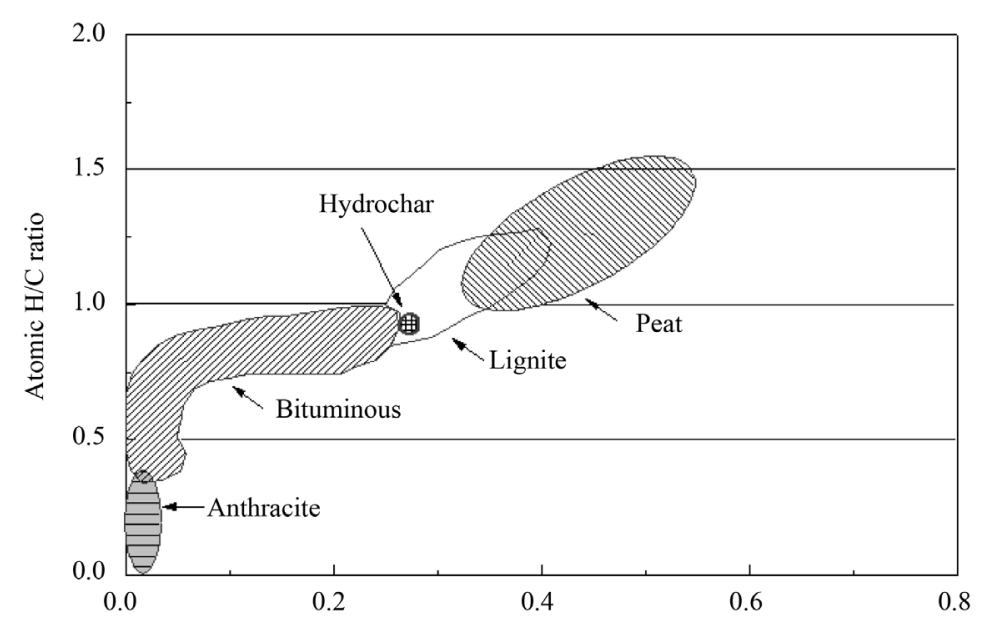

Figure 4. Van Krevelen diagram for the hydrochar. 


$$
\mathrm{HHV}=0.349 \mathrm{C}+1.1783 \mathrm{H}+1.005 \mathrm{~S}-0.1034 \mathrm{O}-0.0015 \mathrm{~N}-0.0211 \mathrm{~A}(\mathrm{MJ} / \mathrm{kg})
$$

where $\mathrm{C}, \mathrm{H}, \mathrm{S}, \mathrm{O}, \mathrm{N}$ and A represent the mass percentages on dry basis of carbon, hydrogen, sulfur, oxygen, nitrogen and ash contents of fuels, respectively.

Moisture of the hydrochar was low, because they were obtained after dried. FC/VM was 1.10 and HHV was $28.38 \mathrm{MJ} / \mathrm{kg}$, showing that it could be use as an alternative fuel.

\subsubsection{Combustion Behavior Analysis}

Figure 5 illustrates the combustion profiles of the hydrochar. For a better evaluation of the different combustion behaviors, the entire combustion profile was divided into several stages according to the rate of weight loss in the DTG curve [19]. Table 4 lists the combustion stages, characteristic temperatures and residue of the hydrochar.

As shown in Figure 5, the overall decomposition of the hydrochar was in the temperature range of $85^{\circ} \mathrm{C}$ $657^{\circ} \mathrm{C}$. Stage D exhibited a peak due to moisture content. Stage $\mathrm{E}$ were in the temperature range of $85^{\circ} \mathrm{C}-342^{\circ} \mathrm{C}$ for the devolatilization and combustion. The stage $\mathrm{F}$ took place in the temperature range of $342^{\circ} \mathrm{C}-647^{\circ} \mathrm{C}$ for the further release of VM and char combustion, respectively [20] [21].

$T_{i}$ refers to the temperature at which fuels begin to burn. $T_{i}$ is a critical parameter to minimize fire and explosion as solid fuel [20]. $T_{m}$ corresponds to DTG peak temperature. $T_{b}$ refers to the temperature at which the rate of weight loss diminishes to $1 \mathrm{wt} \% / \mathrm{min}$ at the end of the combustion profile.

$\mathrm{T}_{\mathrm{i}}$ of the hydrochar was $185^{\circ} \mathrm{C}$, which implied the higher difficulty of ignition. This can be explained by the low VM [21]. $\mathrm{T}_{\mathrm{m}}$ of the hydrochar was $384^{\circ} \mathrm{C}$, so it needed a long reaction time to achieve the maximum decomposition rate. Especially, $\mathrm{T}_{\mathrm{b}}$ of the hydrochar was $657^{\circ} \mathrm{C}$, which implies that it had a high $\mathrm{HHV}$ and it needed a long reaction time to achieve the complete combustion.

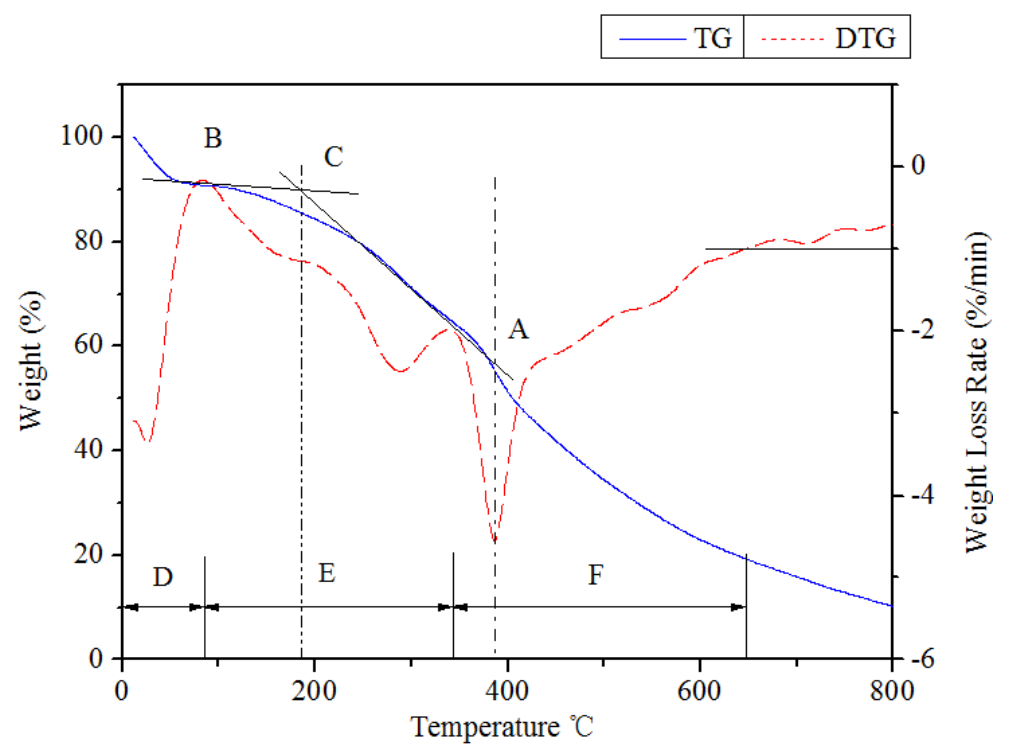

Figure 5. TG-DTG curves for combustion profiles of the hydrochar. Notes, temperature range, $20^{\circ} \mathrm{C}-800^{\circ} \mathrm{C}$; heating rate, $20^{\circ} \mathrm{C} / \mathrm{min}$; air flow rate, $20 \mathrm{~mL} / \mathrm{min}$; an atmospheric pressure.

Table 4. Combustion stages, characteristic temperatures and residue of the hydrochar.

\begin{tabular}{cccccccc}
\hline & Stage $\mathbf{D}\left({ }^{\circ} \mathbf{C}\right)$ & Stage E $\left({ }^{\circ} \mathbf{C}\right)$ & Stage $\mathbf{F}\left({ }^{\circ} \mathbf{C}\right)$ & \multicolumn{2}{c}{ Characteristic temperatures } & Residue \\
\cline { 5 - 7 } & & & $\mathbf{T}_{\mathbf{i}}\left({ }^{\circ} \mathbf{C}\right)$ & $\mathbf{T}_{\mathbf{m}}\left({ }^{\circ} \mathbf{C}\right)$ & $\mathbf{T}_{\mathbf{b}}\left({ }^{\circ} \mathbf{C}\right)$ & $(\mathbf{w t} \%)$ \\
\hline Hydrochar & $\sim 85$ & $85-342$ & $342-647$ & 185 & 384 & 657 & 10.47 \\
\hline
\end{tabular}

Notes, Stage D—Dehydration process, Stage E-Devolatilization and combustion phase, Stage F-Char combustion phase, Last stage-Burnout phase, $\mathrm{T}_{\mathrm{i}}$-Ignition temperature, $\mathrm{T}_{\mathrm{m}}$-Maximum combustion rate temperature, $\mathrm{T}_{\mathrm{b}}$ - Burn out temperature $\left(\mathrm{T}_{\mathrm{b}}\right)$. 


\section{Conclusion}

The nonylphenol ethoxylates waste liquid was effectively converted to hydrochar by HTC process. The optimum condition was that $5 \mathrm{~mL}$ of NPEOs waste liquid was totally solidified with $3 \mathrm{~mL}$ of sulfuric acid at $200^{\circ} \mathrm{C}$ for $24 \mathrm{~h}$. The element composition and HHV (28.38 MJ/kg) of the hydrochar were similar to lignite, showing that it could be used as an alternative fuel.

\section{Acknowledgements}

This study was financially supported by China State Construction Innovation Project (CSCEC-2012-Z-14), Shanghai Education Research and Innovation Project (No: 11ZZ176, 12YZ153) and Shanghai University of Engineering Science Innovation Fund for Graduate Students (No: E1-0903-14-01113).

\section{References}

[1] Soares, A., Guieysse, B., Jefferson, B., Cartmell, E. and Lester, J.N. (2008) Nonylphenol in the Environment: A Critical Review on Occurrence, Fate, Toxicity and Treatment in Wastewaters. Environment International, 34, 1033-1049. http://dx.doi.org/10.1016/j.envint.2008.01.004

[2] Ying, G.G. (2006) Fate, Behavior and Effects of Surfactants and Their Degradation Products in the Environment. Environment International, 32, 417-431. http://dx.doi.org/10.1016/j.envint.2005.07.004

[3] Sharma, V.K., Anquandah, G.A., Yngard, R., et al. (2009) Nonylphenol, Octylphenol, and Bisphenol-A in the Aquatic Environment: A Review on Occurrence, Fate, and Treatment. Journal of Environmental Science and Health, Part A: Toxic/Hazardous Substances and Environmental Engineering, 44, 423-442. http://dx.doi.org/10.1080/10934520902719704

[4] Lu, J., Jin, Q., He, Y.L. and Wu, J. (2007) Biodegradation of Nonylphenol Polyethoxylates under Fe(III)-Reducing Conditions. Chemosphere, 69, 1047-1054. http://dx.doi.org/10.1016/j.chemosphere.2007.04.035

[5] Karci, A., Arslan-Alaton, I., Bekbolet, M., Ozhan, G. and Alpertunga, B. (2014) $\mathrm{H}_{2} \mathrm{O}_{2} / \mathrm{UV}-\mathrm{C}$ and Photo-Fenton Treatment of a Nonylphenol Polyethoxylate in Synthetic Freshwater: Follow-Up of Degradation Products, Acute Toxicity and Genotoxicity. Chemical Engineering Journal, 241, 43-51. http://dx.doi.org/10.1016/j.cej.2013.12.022

[6] Chen, L., Zhou, H.Y., Liu, L and Deng, Y.D. (2007) Mechanism Study on UV-Induced Photodegradation of Nonylphenol Ethoxylates by Intermediate Products Analysis. Chinese Chemical Letters, 18, 473-475. http://dx.doi.org/10.1016/j.cclet.2007.02.004

[7] Liu, G.M., Zheng, S.R., Yin, D.Q., et al. (2006) Adsorption of Aqueous Alkylphenol Ethoxylate Surfactants by Mesoporous Carbon CMK-3. Journal of Colloid and Interface Science, 302, 47-53. http://dx.doi.org/10.1016/j.jcis.2006.06.006

[8] Mumme, J., Eckervogt, L., Pielert, J., et al. (2011) Hydrothermal Carbonization of Anaerobically Digested Maize Silage. Bioresource Technology, 102, 9255-9260. http://dx.doi.org/10.1016/j.biortech.2011.06.099

[9] Funke, A. and Ziegler, F. (2010) Hydrothermal Carbonization of Biomass: A Summary and Discussion of Chemical Mechanisms for Process Engineering. Biofuels Bioproducts \& Biorefining, 4, 160-177. http://dx.doi.org/10.1002/bbb.198

[10] Libra, J.A., Ro, K.S., Kammann, C., et al. (2010) Hydrothermal Carbonization of Biomass Residuals: A Comparative Review of the Chemistry, Processes and Applications of Wet and Dry Pyrolysis. Biofuels, 2, 71-106. http://dx.doi.org/10.4155/bfs.10.81

[11] Dinjus, E., Kruse, A. and Troger, N. (2011) Hydrothermal Carbonization-1. Influence of Lignin in Lignocelluloses. Chemical Engineering \& Technology, 34, 2037-2043. http://dx.doi.org/10.1002/ceat.201100487

[12] Titirici, M.M., Thomas, A., Yu, S.H., Muller, J.O. and Antonietti, M. (2007) A Direct Synthesis of Mesoporous Carbons with Bicontinuous Pore Morphology from Crude Plant Material by Hydrothermal Carbonization. Chemistry of Materials, 19, 4205-4212. http://dx.doi.org/10.1021/cm0707408

[13] Silva, J.D.O., Filho, G.R., Meireles, C.D.S., et al. (2012) Thermal Analysis and FTIR Studies of Sewage Sludge Produced in Treatment Plants. The Case of Sludge in the City of Uberlandia-MG, Brazil. Thermochim Acta, 528, 72-75. http://dx.doi.org/10.1016/j.tca.2011.11.010

[14] Li, M., Li, W. and Liu, S.X. (2011) Hydrothermal Synthesis, Characterization, and KOH Activation of Carbon Spheres from Glucose. Carbohydrate Research, 346, 999-1004. http://dx.doi.org/10.1016/j.carres.2011.03.020

[15] Kang, S., Li, X., Fan, J. and Chang, J. (2012) Characterization of Hydrochars Produced by Hydrothermal Carbonization of Lignin, Cellulose, d-Xylose, and Wood Meal. Industrial and Engineering Chemistry Research, 51, 9023-9031. http://dx.doi.org/10.1021/ie300565d 
[16] Mosa, J., Durán, A. and Aparicio, M. (2015) Sulfonic Acid-Functionalized Hybrid Organic-Inorganic Proton Exchange Membranes Synthesized by Sol-Gel Using 3-Mercaptopropyl Trimethoxysilane (MPTMS). Journal of Power Sources, 297, 208-216. http://dx.doi.org/10.1016/j.jpowsour.2015.06.119

[17] Van Krevelen, D.W. (1993) Coal. 3rd Edition, Elsevier Science Publishers, Amsterdam.

[18] Channiwala, S.A. and Parikh, P.P. (2002) A Unified Correlation for Estimating HHV of Solid, Liquid and Gaseous Fuels. Fuel, 81, 1051-1063. http://dx.doi.org/10.1016/S0016-2361(01)00131-4

[19] He, C., Giannis, A. and Wang, J.Y. (2013) Conversion of Sewage Sludge to Clean Solid Fuel Using Hydrothermal Carbonization: Hydrochar Fuel Characteristics and Combustion Behavior. Applied Energy, 111, 257-266. http://dx.doi.org/10.1016/j.apenergy.2013.04.084

[20] Xu, M. and Sheng, C. (2011) Influences of the Heat-Treatment Temperature and Inorganic Matter on Combustion Characteristics of Cornstalk Biochars. Energy \& Fuels, 26, 209-218. http://dx.doi.org/10.1021/ef2011657

[21] Biagini, E. and Tognotti, L. (2006) Comparison of Devolatilization/Char Oxidation and Direct Oxidation of Solid Fuels at Low Heating Rate. Energy \& Fuels, 20, 986-992. http://dx.doi.org/10.1021/ef0503156 